\title{
Alteraciones fisiológicas asociadas a la infección con Mal de Río Cuarto virus (MRCV) y a fitotoxicidad provocada por su insecto vector (Delphacodes kuscheli Fennah) en trigo
}

\author{
Liliana del V. Di Feo, Irma G. Laguna \& Elvio B. Biderbost \\ Instituto de Fitopatología y Fisiología Vegetal, Instituto Nacional de Tecnología Agropecuaria, IFFIVE- INTA, Córdoba, \\ Argentina
}

Autor para correspondencia: Liliana del V. Di Feo, e-mail: ldifeo@correo.inta.gov.ar

\section{RESUMEN}

Mal de Río Cuarto virus en trigo provoca una enfermedad resultante de la acción combinada con su principal vector, Delphacodes kuscheli. La severa sintomatología inducida por virus e insecto condujo a determinar la posible existencia de alteraciones fisiológicas en el cultivar de trigo ProINTA Federal, infectado artificialmente con dos aislamientos geográficamente distantes del MRCV y sometido a picadura de insectos no virulíferos, respectivamente, en tres estadios fenológicos. ProINTA Federal fue picado por insectos no virulíferos e inoculado en la primera hoja emergiendo del coleóptilo, en la cuarta y quinta hojas desplegadas, respectivamente. La condición sanitaria de los diferentes tratamientos fue constatada mediante ELISA. Las plantas tratadas manifestaron alteraciones fisiológicas con similares variaciones entre estadios fenológicos. Azúcares solubles totales, almidón y proteínas solubles incrementaron significativamente su contenido en plantas infectadas por MRCV. En plantas PS y con MRCV, el contenido de clorofilas disminuyó marcadamente y lo inverso sucedió con el malondialdehído, lo que indicaría daño oxidativo por estrés en las mismas. No existieron diferencias entre estadios fenológicos y las variaciones de los indicadores de alteraciones fisiológicas considerados, excepto para el incremento de almidón, significativamente superior en plantas inoculadas en la primera hoja emergiendo del coleóptilo.

Palabras clave: infección viral, toxicidad por insectos, azúcares solubles, almidón, proteínas, clorofilas, malondialdehído, estadios fenológicos.

\begin{abstract}
Physiological alterations associated to the Mal de Rio Cuarto virus (MRCV) infection and to vector (Delphacodes kuscheli Fennah) phytotoxicity in wheat

Mal de Rio Cuarto virus produces a wheat disease, resulting from the combined action of this pathogen and its main vector, Delphacodes kuscheli. Knowing that viruses and insects cause a severe symptomatology in different genotypes, the objective of this work was to determine the possible physiological alterations in three phenological stages of wheat (cv ProINTA Federal) inoculated by two geographically distant MRCV isolates and exposed to non viruliferous insects. Treatments were run at three plant stages: first leaf emergence through coleoptile, four and five unfolded leaves. The health status of these plants was confirmed by ELISA. Physiological alterations were observed in both infected plants and plants exposed to non viruliferous insects (PS). The total soluble sugar, starch and soluble protein contents increased remarkably in the plants infected by MRCV. While chlorophyll content decreased considerably in PS and MRCV infected plants, malondialdehyde levels increased in both cases. These variations could indicate oxidative damage associated to biotic stress in these plants. The physiological alterations were similar on the different phenological stages. Only the starch increase was significantly higher in plants infected at the first leaf emergence from the coleoptile.
\end{abstract}

Keywords: virus infection, insect toxicity, soluble sugars, starch, proteins, chlorophylls, malondialdehyde, phenologycal stages.

\section{INTRODUCCIÓN}

Mal de Río Cuarto es la enfermedad más importante del maíz, cultivo en el que puede llegar a ocasionar pérdida en el rendimiento de hasta $70 \%$, en años de gran incidencia (March et al., 1993). A comienzos de la década del 80 se describieron detalladamente sus síntomas y se determinó la naturaleza viral de la misma (Bradfute et al., 1981; Nome et al., 1981). Su agente causal, Mal de Río Cuarto virus (MRCV), pertenece a la familia Reoviridae, género Fijivirus, con partículas de forma icosaédrica de 65-70 nm de diámetro y con 10 segmentos de doble cadena de RNA (Bradfute et al., 1981; Milne, 1983; Boccardo \& Milne, 1984; Conti, 1984; Uyeda \& Milne, 1995). Inicialmente se consideró que era una raza geográfica del Maize rough dwarf virus (MRDV) detectado en Italia (Conti, 1988), pero estudios posteriores de análisis comparativos de secuencia nucleotídica de distintos segmentos genómicos, permitieron concluir que el MRCV constituye una entidad viral diferente (Distéfano et al., 2002, 2003).

Como todos los reovirus, MRCV se difunde en la naturaleza sólo por acción de insectos. Sus partículas 
confinadas al floema no son transmisibles mecánicamente. Delphacodes kuscheli Fennah, "chicharrita" perteneciente al orden Hemiptera, familia Delphacidae es el principal vector del MRCV (Remes Lenicov et al., 1985; Ornaghi et al., 1993; 1999). La modalidad de transmisión de los Fijivirus es persistente propagativa (una vez adquirido, el virus se multiplica dentro del cuerpo del vector, el cual permanece infectivo durante toda su vida) (Milne \& Lovisolo, 1977; Arneodo, 2002a).

Respecto a los hospedantes naturales del MRCV, éstos pertenecen casi en su totalidad a la familia Poaceae; algunos de ellos son cultivos anuales invernales como avena y trigo (Rodríguez Pardina et al., 1998) los que, además de ser reservorios del virus, resultan propicios para la cría, alimentación y oviposición de la chicharrita que lo transmite, que luego migra hacia plantas de maíz en sus primeros estadios de crecimiento. De este modo, el trigo constituye un importante eslabón en la cadena epidemiológica de la enfermedad (Remes Lenicov et al., 1985; Teson et al., 1986; Ornaghi et al., 1993).

Basándose en estas observaciones, Rodríguez Pardina et al. (1998) efectuaron estudios tendientes a la detección e identificación del virus del Mal de Río Cuarto en cultivos de trigo del área endémica (Río Cuarto, Sampacho y La Carlota, Provincia de Córdoba, Argentina) acentuándose los mismos en la observación de síntomas. Estas investigaciones permitieron establecer que, en estado vegetativo, las plantas infectadas presentaban mayor cantidad de macollos, acortamiento de entrenudos, aspecto achaparrado, hojas más cortas, erectas y de consistencia coriácea con engrosamiento de nervaduras y en estado reproductivo, acortamiento de cañas, engrosamiento de las paredes celulares, hojas con bordes aserrados y enroscadas sobre sí mismas, curvamiento de espigas con acortamiento del raquis y esterilidad total o parcial (Rodríguez Pardina et al., 1998). Posteriormente, ensayos experimentales en los que se incluían distintos cultivares de la gramínea, corroboraron la gravedad de síntomas exhibidos en todos ellos: plantas achaparradas, hojas con área reducida, algunas enrolladas en tirabuzón, con bordes recortados $\mathrm{y}$ nervaduras hinchadas. Cuando se formaban espigas, éstas eran vanas y de crecimiento exiguo (Liliana Di Feo, datos no publicados). Complementariamente, en dichos experimentos se comprobó que el principal insecto vector del MRCV (Delphacodes kuscheli Fennah) es responsable durante la alimentación, de la inducción de un marcado efecto fitotóxico de tipo sistémico, manifestado a través de la disminución notable del crecimiento, reducción del área foliar y presencia de clorosis general y estrías cloróticas en hojas. Estos daños son semejantes a los ocasionados por otros insectos hemípteros, tales como: los áfidos Therioaphis trifolii maculata Buckton en alfalfa, Acyrtosiphon pisum Harris en arveja (Madhusudhan \& Miles, 1998), los cicadélidos Empoasca spp., causal de "hopperburn" en diferentes plantas (Backus et al., 2005) y Dalbulus maidis De long \& Wolcott en maíz (Gassen, 2000), el aleuródido
Bemisia tabaci (Gennadius) en varias especies vegetales y el delfácido Nilaparvata lugens (Stal) en arroz (Watanabe \& Kitagawa, 2000), entre otros. Los mencionados son insectos toxicógenos que al tomar savia de sus hospedantes, simultáneamente inyectan toxinas a través de su saliva y producen distintas alteraciones en los vegetales, las cuales en general, conducen al debilitamiento de la planta, detención del crecimiento y disminución general de sus rendimientos. En el caso de A. pisum y T. trifolii maculata, análisis electroforéticos y bioquímicos revelaron que las toxinas son enzimas tales como pectinasas, peroxidasas y catecoloxidasas presentes en la saliva expulsada por ambas especies. En cuanto al "hopperburn" (achaparramiento y amarillamiento, apariencia de quemado del follaje) causado por Empoasca spp. no es sólo consecuencia de la fitotoxicidad de la saliva inyectada en el floema, sino también una respuesta a la herida en la planta producida por el movimiento del estilete, la cual es luego exacerbada por la saliva (Backus et al., 2005). De este modo, se llegó a la conclusión de que en la expresión de la virosis provocada por el mal de Río Cuarto en trigo se encuentra involucrado no sólo el virus, mas que existe una acción combinada de éste con su vector (Liliana Di Feo, datos no publicados). Por otra parte, la severa sintomatología exhibida por los cultivares estudiados al ser infectados con MRCV o sometidos a la acción del vector no infectivo, condujo a la presunción de la existencia de alteraciones de tipo fisiológico en ambos casos. Al respecto, si bien no hay suficientes antecedentes en relación al efecto de los virus vegetales sobre la fisiología del hospedante, existen estudios que indican la ocurrencia de alteraciones relacionadas con la replicación viral y la expresión de síntomas. Así, por ejemplo, las infecciones por Sunflower chlorotic mottle virus (SuCMoV) causan moteado clorótico y notable reducción del crecimiento en plantas de girasol, síntomas que redundan en importantes disminuciones de rendimiento en esta oleaginosa y que son comunes a diversas enfermedades virales (Dujovny et al., 1998). Investigaciones recientes indican que dichos efectos estarían relacionados con una alteración en la síntesis de compuestos carbonados y con la ocurrencia de estrés oxidativo. Pudo observarse que las hojas de girasol con síntomas de virus tuvieron mayor concentración de azúcares solubles, de almidón y de malondialdehído (MDA) que las hojas de plantas sanas (Arias et al., 2005). Lo inverso sucedió con el contenido de clorofilas que fue menor en hojas sintomáticas, situación análoga a la estudiada en batata infectada con "enanismo clorótico" (Di Feo et al., 1995).

En cuanto al MDA, que es un intermediario de la peroxidación de lípidos de las membranas celulares, junto con las alteraciones en la concentración de clorofilas y la salida pasiva de electrolitos (daño en membrana), son indicadores de estrés oxidativo en plantas (Pastori \& Trippi, 1992; Iturbe-Ormaetxe et al., 1998).

Dada la inexistencia de estudios previos relativos a disturbios fisiológicos que se producen en el patosistema 
trigo-MRCV- D. kuscheli, se planteó el presente estudio que tuvo como objetivo: determinar a través de la medición de distintas variables indicadoras, la ocurrencia de alteraciones fisiológicas en un cultivar de trigo infectado artificialmente con dos aislamientos geográficamente distantes del MRCV y sometido a picadura por insectos no virulíferos, respectivamente, en tres estadios fenológicos diferentes.

\section{MATERIALES Y MÉTODOS}

\section{Generación del tratamiento "plantas picadas por insectos} no virulíferos" y "plantas infectadas con MRCV"

Con el propósito de implementar un ensayo de campo en el área experimental del Instituto de Fitopatología y Fisiología Vegetal del Instituto Nacional de Tecnología Agropecuaria (IFFIVE- INTA), en Córdoba, Argentina, durante el año 2003 plantas del cultivar ProINTA Federal fueron sometidas a picadura de insectos no virulíferos y a infección artificial con dos aislamientos del MRCV, en tres estadios fenológicos de la planta. En las transmisiones experimentales del MRCV, mediante D. kuscheli, se emplearon los aislamientos del Noroeste Argentino (NOA), procedente de Tafí del Valle, provincia de Tucumán (Virla et al., 1998), y de la Zona Endémica (ZE), proveniente del departamento Río Cuarto, sur de la provincia de Córdoba, respectivamente. Ambos aislamientos fueron renovados periódicamente mediante inoculaciones con el vector infectado con cada uno de ellos y se mantuvieron en invernáculo. En dichas transmisiones con D. kuscheli, el tiempo de adquisición fue de dos días, el de latencia de 10 días y el de infección de 48 h (Truol et al., 2001).

Para generar el tratamiento de plantas picadas por insectos no virulíferos (PS), los mismos se alimentaron de las plántulas sanas de trigo por un período de $48 \mathrm{~h}$. En la obtención de plantas PS e infectadas por uno u otro aislamiento del MRCV se utilizaron tres insectos por planta, ya que, en ensayos previos en los que se incluyeron diferentes genotipos de trigo, se comprobó que ese número era el mínimo necesario para que la plántula de trigo inoculada con el virus o sometida a la acción de insectos no virulíferos se infectara o manifestara fitotoxicidad, sin llegar a morir (Liliana Di Feo, datos no publicados). Se contemplaron los siguientes momentos de infección o de picadura de insectos no virulíferos: a) plántulas con primera hoja emergiendo del coleóptilo (dos días desde emergencia), b) plántulas con cuatro hojas desplegadas (17 días desde emergencia) y c) plántulas con cinco hojas desplegadas (32 días desde emergencia). La totalidad del procedimiento descrito se condujo en fitotrón $\left(24 \pm 1{ }^{\circ} \mathrm{C}\right.$, fotoperíodo de 12 $\mathrm{h}$ de luz, 10.000 lux y $50 \pm 5 \% \mathrm{HR}$ ).

\section{Ensayo de campo}

Luego de aplicaciones alternadas de Decis (Deltametrina 2,5\%) y aficida Duperial (Pirimicarb 50\%: $0,5 \mathrm{~g} / \mathrm{l})$, con el fin de eliminar las distintas formas del insecto, las plantas tratadas se rusticaron y transplantaron en el campo experimental del IFFIVE-INTA, bajo jaula antiáfidos, de tela de polietileno color cristal, de alta densidad (10 x 16 hilos/pulgada cuadrada), que provee total protección contra insectos pequeños como las chicharritas y no influye sobre la fisiología de las plantas que se desarrollan en su interior, al permitir una adecuada ventilación y paso de luz (Cafrune et al., 2006). Complementariamente, se realizaron aplicaciones periódicas y quincenales de los insecticidas mencionados (la primera, al momento del transplante) con el fin de preservar la condición sanitaria de las diferentes variantes. Se siguió un diseño en parcelas divididas en bloques completos al azar, con tres repeticiones. Sólo se incluyeron en el ensayo plantas con signos conspicuos de oviposición (manchas ovales violáceas en la base del tallo) y de alimentación del insecto (manchas cloróticas y/o de apariencia oleosa en la lámina foliar). El control negativo correspondió a plantas de trigo del cultivar ProINTA Federal sano (S). El factor condición sanitaria, con cuatro 'niveles' (S, PS, ZE o NOA), se asignó a la parcela principal y el factor fenológico con tres estadios, a la parcela secundaria. Las parcelas estuvieron constituidas por 10 plantas a 0,10 $\mathrm{m}$ entre ellas. La distancia entre surcos fue de $0,35 \mathrm{~m}$. El transplante de las plántulas tratadas en diferentes momentos de su crecimiento fue realizado simultáneamente.

\section{Confirmación de la condición sanitaria de las plántulas muestreadas}

La ausencia de MRCV en plantas sanas y picadas por insectos no virulíferos y su presencia en las inoculadas con los aislamientos ZE y NOA, fueron confirmadas mediante DAS-ELISA (Clark \& Adams, 1977), empleando un suero anti-MRCV producido en el IFFIVE (Rodríguez Pardina et al., 1998).

Preparación de reactivos de diagnóstico: a partir del suero contra MRCV, se purificó gamablobulina por precipitación con sulfato de amonio al $50 \%$ y posterior cromatografía en columna de DEAE Sephacel (Sigma Chemical Co, St. Louis) preparada en tampón fosfato salino diluido a la mitad (PBS, fosfato $0,02 \mathrm{M}$; más ClNa-K $0,15 \mathrm{M}$, $\mathrm{pH} 7,4)$. La misma fue eluida en el tampón mencionado y se colectaron fracciones de $1 \mathrm{ml}$, de las que se monitoreó su absorbancia $\left(\mathrm{A}_{280}\right)$. Posteriormente se preparó el conjugado enzimático, para lo cual $1 \mathrm{ml}$ de la inmunoglobulina ( $\operatorname{IgG})$ con $\mathrm{A}_{280}=1,4$ (corresponde a $1 \mathrm{mg} / \mathrm{ml}$ ) fue conjugada con fosfatasa alcalina (Type VII T, Sigma Chemical Co.) de acuerdo al protocolo de Clark \& Adams (1977).

DAS-ELISA: para confirmar la condición sanitaria (S, PS, ZE y NOA) de cada una de las plantas del ensayo de campo, se tomó la tercera hoja desplegada (a partir del ápice de la planta) a los 60 días desde la emergencia en invernáculo y al mes del transplante en campo. La misma fue macerada en tampón PBS $+0,05 \%$ de tween $20+2 \%$ de polivinil pirrolidona (PVP) en proporción 1:5 (p/v).

La placas soporte de la prueba (Nunc-Immunoplate MaxiSorp), de 96 celdillas, fueron cubiertas con $1 \mu \mathrm{g} / \mathrm{ml}$ de IgG en carbonato de sodio $0,05 \mathrm{M} ; \mathrm{pH} 9,6$, e incubadas a 
$37^{\circ} \mathrm{C}$ por $4 \mathrm{~h}$. Posteriormente, se adicionó el antígeno a las celdillas y el período de incubación fue de $18 \mathrm{~h}$ a $5^{\circ} \mathrm{C}$. A continuación, la placa a la que se le agregó $\operatorname{IgG}$ específica para MRCV conjugada con fosfatasa alcalina (conjugado enzimático diluido 1:1000 en tampón conjugado: PBS + $0,05 \%$ de tween $20+2 \%$ de PVP $+0,2 \%$ de ovoalbúmina) se llevó a $37^{\circ} \mathrm{C}$ por $4 \mathrm{~h}$. Entre los pasos mencionados de la prueba, se realizaron tres lavados, de tres minutos cada uno, con PBS $+0,05 \%$ de tween 20 . Luego de colocar el sustrato $(0,75 \mathrm{mg} / \mathrm{ml}$ de p-nitrofenilfosfato disódico [Sigma Chemical Co.] en $10 \%$ de dietanolamina, $\mathrm{pH} 9,8)$, la reacción fue cuantificada usando un lector de placas de ELISA (Dynatech MR 4000®). El punto crítico o umbral (valor de $\mathrm{A}_{405}$ a partir del cual una muestra es considerada positiva para MRCV), se estableció como la media de $\mathrm{A}_{405}$ de los controles sanos más tres veces la desviación estándar (se emplearon seis controles sanos por placa). Para comparar las lecturas de las diferentes placas, se calculó la absorbancia relativa (AR) dividiendo cada valor de $\mathrm{A}_{405}$ por el punto crítico mencionado, considerando como enfermas las muestras con AR igual o superior a 1. Los registros de AR (que estima de manera indirecta la concentración viral) en plantas infectadas con los aislamientos ZE y NOA del MRCV fueron posteriormente sometidos a ANAVA y complementariamente, permitieron calcular el porcentaje de plantas infectadas con aislamiento ZE o NOA del MRCV. En el caso de plantas picadas por insectos no virulíferos (PS), cuya condición de libres de MRCV fue confirmada por DAS-ELISA $(\mathrm{AR}<1)$, se estableció el porcentaje de plantas con síntomas de fitotoxicidad.

\section{Variables indicadoras de alteraciones fisiológicas} Muestreo de plántulas para determinación de variables indicadoras de alteraciones fisiológicas: el muestreo se llevó a cabo a los 60 días de la emergencia de las plántulas en invernáculo (un mes desde el transplante en el campo). Las distintas mediciones se realizaron en dos plantas por bloque (seis plantas en total) para cada combinación de condición sanitaria (S, PS, ZE y NOA) y estadio fenológico en que la planta fue sometida a picadura por insecto no infectivo o a infección por uno u otro aislamiento del MRCV (primera hoja emergiendo del coleóptilo; plántulas con cuatro hojas desplegadas; plántulas con cinco hojas desplegadas, respectivamente).

Determinaciones relativas a variables indicadoras de alteraciones fisiológicas: se efectuaron diferentes mediciones indicativas de alteraciones fisiológicas tales como contenido de hidratos de carbono solubles e insolubles, proteínas solubles, clorofilas y MDA en la hoja inmediata inferior a la última desplegada, con síntomas típicos de fitotoxicidad causadas por insectos no virulíferos (en plantas PS) o de virosis (en plantas infectadas con MRCV). El control negativo correspondió a hojas de la posición indicada, provenientes de plantas sanas del cv ProINTA Federal. A los fines de determinar contenido de azúcares solubles totales y almidón ( $\mu \mathrm{g} / \mathrm{mg}$ PF) se siguieron las técnicas de Guan \& Janes (1991) y Sumner \& Somers (1944), respectivamente. El contenido de proteínas solubles ( $\mu \mathrm{g} / \mathrm{mg}$ PF) de los extractos se estimó con la técnica del Coomassie Brilliant Blue G-250 (Bradford, 1976). La medición de contenido de clorofilas ( $\mu \mathrm{g} / \mathrm{mg}$ PF) se efectuó según Tetley \& Thimann (1974) y la del contenido de MDA $(\mu \mathrm{M} / \mathrm{mg}$ PF) según Heath \& Packer (1968).

Complementariamente se calcularon los incrementos o disminuciones porcentuales del contenido de azúcares solubles totales, almidón, proteínas solubles, MDA y clorofilas, relativos a plantas sanas, mediante la transformación de cada variable utilizando las siguientes fórmulas:

$\%$ incremento $=\underline{\text { (media variable en ZE, NOA o PS - media variable en plantas sanas) }} \times 100$

media variable en plantas sanas

$\%$ disminución $=($ media variable en plantas sanas - media variable en ZE, NOA o PS $) \times 100$

media variable en plantas sanas

Para cada variable transformada se analizaron las diferencias entre estadios fenológicos y entre condiciones sanitarias y la probable existencia de interacción entre estadio fenológico y condición sanitaria. Para ello se realizaron análisis univariados de varianza, con un nivel de probabilidad de error inferior al $5 \%$, mediante el empleo del programa estadístico Infostat 2004 (InfoStat, 2004).

\section{RESULTADOS Y DISCUSIÓN}

\section{Mediciones relativas a fitotoxicidad por insectos no virulíferos y a infección por MRCV}

En las tres repeticiones del ensayo de campo pudo confirmarse la ausencia de infección viral en las plantas sanas (S) y en las picadas por insectos no virulíferos (PS), en los tres estadios fenológicos considerados (primera hoja emergiendo del coleóptilo, cuatro y cinco hojas desplegadas), que posteriormente fueron empleados para realizar las determinaciones de las alteraciones fisiológicas. En ambos casos, los registros de absorbancia relativa (AR) obtenidos a partir de las pruebas de DAS-ELISA fueron menores a 1 .

Por otro lado, en las plantas infectadas con aislamiento de la Zona Endémica (ZE) y del Noroeste Argentino (NOA) de MRCV, que fueron usadas con el mismo fin, se corroboró la presencia del mencionado virus $(\mathrm{AR}>1)$.

Concentración viral (AR): el ANAVA reveló la ausencia de diferencias significativas entre momentos de infección $(\mathrm{p}=0,4348)$ y entre ambos aislamientos del MRCV $(p=0,0509)$ en la concentración viral, estimada indirectamente mediante AR (tabla 1).

Sintomatología: las plantas picadas por insectos no virulíferos (con AR $<1$ en DAS-ELISA) exhibieron síntomas de igual severidad en los tres estadios fenológicos del tratamiento (disminución de crecimiento, debilitamiento, reducción del área foliar, clorosis generalizada y presencia de estrías cloróticas en hojas). En el caso de las plantas 
infectadas con aislamiento ZE y NOA de MRCV, con valores de AR $>1$ en la prueba serológica, tampoco hubo diferencias de severidad de síntomas entre estadios fenológicos de infección con el virus, ni entre ambos aislamientos. En todos los casos, la sintomatología exhibida fue de reducción marcada del crecimiento, presencia de hojas coriáceas con nervaduras hinchadas y bordes recortados y ausencia de espigas o bien, espigas vanas.

Porcentaje de plantas afectadas por insectos no virulíferos y porcentaje de plantas infectadas con MRCV: en la tabla 2 puede observarse el porcentaje de plantas con síntomas de fitotoxicidad causada por la picadura de insectos no virulíferos y el porcentaje de plantas infectadas con el aislamiento ZE y NOA del MRCV. El ANAVA reveló la existencia de diferencias significativas estadísticamente $(\mathrm{p}=$ 0,0174 ) entre condiciones sanitarias, ya que los menores porcentajes fueron para plantas afectadas por insectos no virulíferos (70\%), en tanto que los porcentajes de plantas infectadas con los aislamientos ZE y NOA no discreparon entre sí ( 83 y $88 \%$, respectivamente). En ningún caso fueron detectadas diferencias significativas entre los tres estadios fenológicos considerados $(\mathrm{p}=0,2701)$.

TABLA 1 - Valores de absorbancia relativa (AR= A405 muestra/ media A405 controles sanos +3 desvíos estándar) de plantas de trigo cv ProINTA Federal infectadas con aislamiento de Zona Endémica (ZE) y del Noroeste Argentino (NOA) del Mal de Río Cuarto virus (MRCV) en tres estadios fenológicos diferentes (1: primera hoja emergiendo del coleóptilo, 2: cuarta hoja desplegada y 3: quinta hoja desplegada) (promedio + error estándar). Letras iguales indican ausencia de diferencias significativas $(p>0,05)$

\begin{tabular}{lcc}
\hline \hline $\begin{array}{l}\text { Estadío } \\
\text { fenológico }\end{array}$ & NOA & ZE \\
\hline 1 & $11,01 \pm 1,15$ (a) & $7,92 \pm 2,17$ (a) \\
2 & $20,84 \pm 8,98$ (a) & $7,85 \pm 2,52$ (a) \\
3 & $18,98 \pm 7,32$ (a) & $8,13 \pm 1,90$ (a) \\
\hline
\end{tabular}

TABLA 2 - Porcentaje de plantas de trigo cv ProINTA Federal afectadas por fitotoxicidad provocada por la picadura de insectos no virulíferos (PS) e infectadas por aislamiento de Zona Endémica (ZE) y del Noroeste Argentino (NOA) del Mal de Río Cuarto virus (MRCV) en tres estadios fenológicos diferentes (1: primera hoja emergiendo del coleóptilo, 2: cuarta y 3: quinta hojas desplegadas) (promedio + error estándar). Letras iguales indican ausencia de diferencias significativas

\begin{tabular}{lcccc}
\hline \hline \multirow{2}{*}{$\begin{array}{l}\text { Condición } \\
\text { Sanitaria }\end{array}$} & \multicolumn{3}{c}{ Estadío fenológico } \\
\cline { 2 - 5 } & & $\mathbf{1}$ (a) & $\mathbf{2}$ (a) & $\mathbf{3}$ (a) \\
\hline PS (a) & $65,30 \pm 9,25$ & $64,07 \pm 4,07$ & $80,17 \pm 13,07$ \\
NOA (b) & $76,67 \pm 3,33$ & $93,33 \pm 3,33$ & $80,00 \pm 5,77$ \\
ZE (b) & $83,33 \pm 6,67$ & $96,67 \pm 3,33$ & $83,33 \pm 8,82$ \\
\hline
\end{tabular}

\section{Variables indicadoras de alteraciones fisiológicas}

$\mathrm{Se}$ registraron diferencias estadísticamente significativas $(p<0,05)$ entre condiciones sanitarias, en todas las variables indicadoras de alteraciones fisiológicas provocadas por estrés biótico. Es decir, tanto la picadura del insecto no infectivo como la infección del virus desencadenan dichas alteraciones en plantas de trigo (Figura1).

\section{Contenido de azúcares solubles totales y de almidón}

El contenido de azúcares solubles fue superior en plantas afectadas por el MRCV que en plantas sanas $(8,20$ $\mu \mathrm{g} / \mathrm{mg} \mathrm{PF}$ ), sin diferencias entre ambos aislamientos (29 $\mu \mathrm{g} / \mathrm{mg}$ PF para ZE y $31 \mu \mathrm{g} / \mathrm{mg}$ PF para NOA). La picadura de insectos no virulíferos no alteró significativamente los niveles normales de azúcares y sólo provocó un aumento poco significativo con respecto a los controles sanos $(11,18$ $\mu \mathrm{g} / \mathrm{mg}$ ) (Figura $1 \mathrm{~A}$ ).

En el caso del contenido de almidón, la situación que se presentó fue similar a la anterior. Frente al estrés causado por el virus, se incrementaron los valores de almidón en los tejidos foliares $(15 \mu \mathrm{g} / \mathrm{mg}$ PF para ZE y $16 \mu \mathrm{g} / \mathrm{mg}$ PF para NOA) respecto a plantas sanas $(8,3 \mu \mathrm{g} / \mathrm{mg} \mathrm{PF})$, lo que no sucedió de manera significativa cuando la planta fue sometida a fitotoxicidad por insectos $(9,4 \mu \mathrm{g} / \mathrm{mg}$ PF) (Figura 1 B).

Respecto al incremento de la concentración de azúcares solubles y de almidón en plantas de trigo infectadas con MRCV, se conoce que, si bien algunos virus parecen tener poca influencia sobre los hidratos de carbono en hojas, otros pueden alterar su tasa de síntesis y de translocación. Debido a que la mayoría de los estudios al respecto fueron realizados a partir de pocas enfermedades, no es posible hacer generalizaciones suficientemente firmes sobre los cambios en los carbohidratos; sin embargo, dos efectos comunes en infecciones virales son: 1) el aumento en las concentraciones de glucosa, fructosa y sacarosa de hojas infectadas y 2) la reducción en la translocación de hidratos de carbono fuera de las hojas (Hull, 2002). En relación al primero de ellos, se considera que el incremento en la concentración de azúcares solubles sería necesario para la replicación viral (Sindelárová et al., 1999). En cuanto al efecto mencionado en segundo término, en algunos virus de floema, tales como el BYV (Beet yellows virus), la reducida exportación de los hidratos de carbono desde las hojas conduce a la acumulación de los fotoasimilados en la lámina foliar, lo que induce a su engrosamiento y enrollamiento (Hull, 2002). Esto podría explicar en las infecciones de trigo con MRCV, la aparición de síntomas vinculados con dicha acumulación, tales como la presencia de hojas coriáceas y enroscadas en tirabuzón.

Por otro lado, en observaciones al microscopio electrónico de secciones ultrafinas practicadas en hojas de plantas sometidas a infección viral se detectaron cloroplastos deformados, agrupados, globosos y con vesículas, con tilacoides desorganizados, tal como fuera indicado por Arneodo et al. (2002 b) y con acumulación de almidón (Liliana Di Feo, datos no publicados). De acuerdo con esto, 

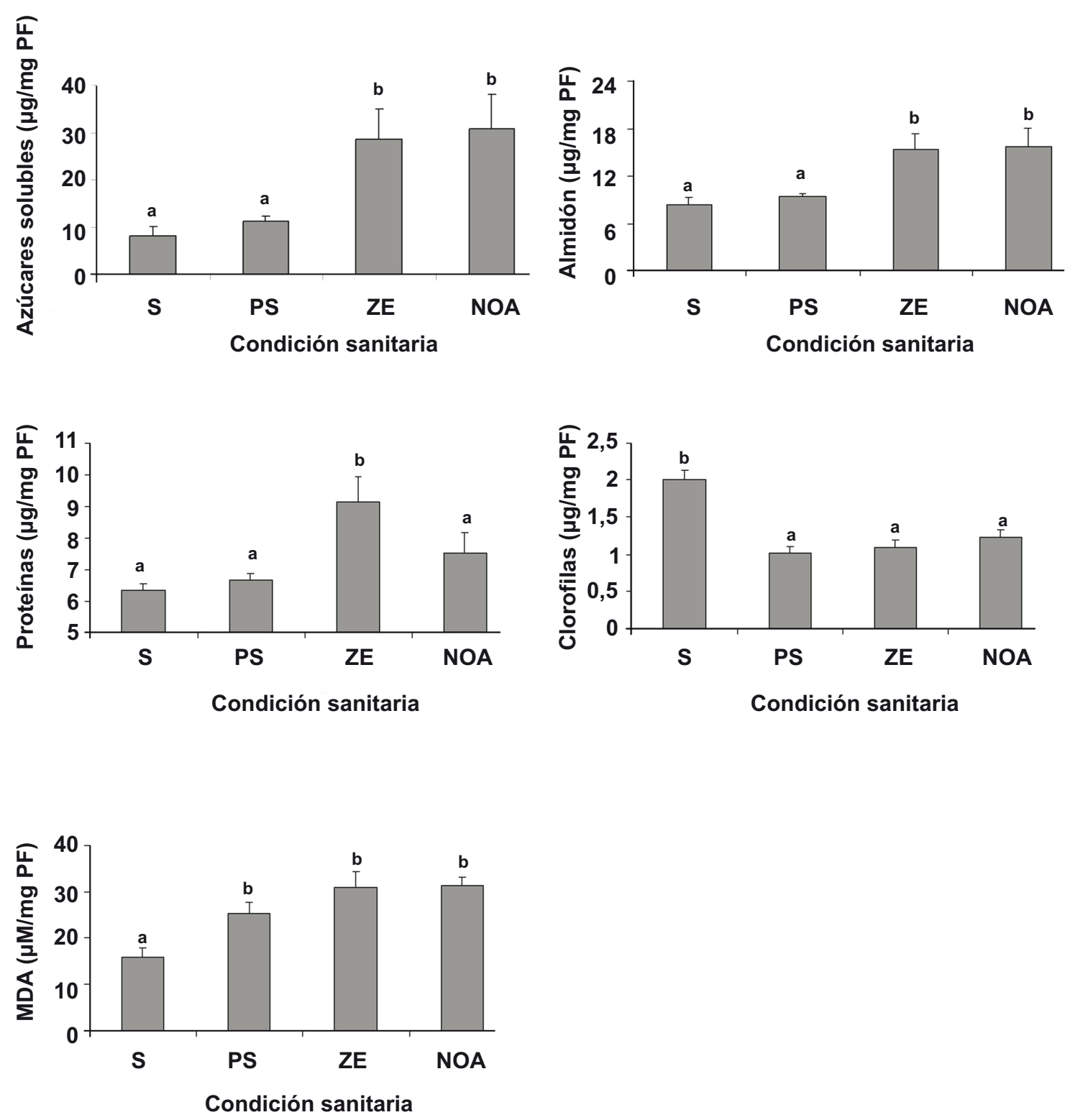

FIGURA 1 - A. Contenido de azúcares solubles totales ( $\mu \mathrm{g} / \mathrm{mg}$ PF); B. contenido de almidón ( $\mu \mathrm{g} / \mathrm{mg}$ PF); C. contenido de proteínas solubles ( $\mu \mathrm{g} / \mathrm{mg} \mathrm{PF})$; D. contenido de clorofilas $(\mu \mathrm{g} / \mathrm{mg}$ PF) y; E. contenido de MDA ( $\mu \mathrm{M} / \mathrm{mg}$ PF) en plantas de trigo cv ProINTA Federal sanas (S), picadas por insectos no virulíferos (PS) e infectadas con aislamiento de Zona Endémica (ZE) y del Noroeste Argentino (NOA) del Mal de Río Cuarto virus (MRCV).

es evidente que tal como sucede en infecciones de girasol con $\mathrm{SuCMoV}$ (Arias et al., 2003), el incremento de azúcares solubles en hojas de plantas de trigo afectadas por MRCV no provendría de la hidrólisis del almidón, sino de un reciclaje de otros componentes celulares. Estos cambios en el metabolismo del carbono pueden resultar en alteraciones en el transporte de electrolitos que culminan en la generación de especies activas de oxígeno (EAOs) (Arias et al., 2005).

\section{Contenido de proteínas solubles}

El contenido de proteínas solubles fue significativamente más alto en plantas infectadas con el aislamiento ZE del MRCV $(9 \mu \mathrm{g} / \mathrm{mg} \mathrm{PF})$ que para las restantes condiciones sanitarias, las cuales no se diferenciaron entre sí. No obstante, el aislamiento NOA también provocó un incremento $(7,54 \mu \mathrm{g} / \mathrm{mg} \mathrm{PF})$, aunque no estadísticamente significativo, en relación a plantas sanas $(6,33 \mu \mathrm{g} / \mathrm{mg} \mathrm{PF})$. En plantas PS no hubo variación respecto a dichos controles $(6,7 \mu \mathrm{g} / \mathrm{mg}$ PF) (Figura $1 \mathrm{C}$ ).

Se conoce que la cubierta proteica de virus tales como el TMV, puede representar aproximadamente la mitad del total de proteínas de la hoja enferma (Hull, 2002). Basados en esto, sería factible considerar que el incremento de la concentración proteica en plantas de trigo enfermas podría ser consecuencia de la infección con MRCV. 


\section{Contenido de clorofilas y de MDA}

El contenido de clorofilas fue significativamente menor en relación a los controles negativos: $(2 \mu \mathrm{g} / \mathrm{mg}$ PF), en hojas de plantas PS: $(1,02 \mu \mathrm{g} / \mathrm{mg} \mathrm{PF})$ o infectadas con aislamiento ZE: $(1,11 \mu \mathrm{g} / \mathrm{mg}$ PF) y NOA: $(1,24 \mu \mathrm{g} / \mathrm{mg}$ PF $)$ del MRCV, los que no discreparon entre sí (Figura $1 \mathrm{D}$ ). Evidentemente, esta disminución en plantas picadas por insectos no virulíferos y en infectadas con el virus, junto con la alteración de la estructura de los cloroplastos (Liliana Di Feo, datos no publicados), conduce a una menor actividad fotosintética, que es quizá el modo más común por el cual la infección produce la reducción del tamaño de la planta (Hull, 2002).

En el caso del malondialdehído (MDA) sucedió lo inverso que para clorofilas, ya que su concentración aumentó en hojas de plantas tratadas (PS o infectadas con aislamiento ZE y NOA del MRCV) con respecto a las sanas (Figura $1 \mathrm{E}$ ). El incremento en el contenido de MDA, sumado a la degradación de los pigmentos clorofílicos en hojas de plantas tratadas (PS e infectadas con MRCV), indican la generación de estrés oxidativo que probablemente se debería a daños en las membranas de los cloroplastos, según lo evidencia la pérdida de clorofilas sufrida por tales plantas. Dicho daño oxidativo se asocia con la generación de especies activas de oxígeno (EAO's), tales como ión superóxido, peróxido de hidrógeno y radical hidroxilo, las cuales pueden reaccionar con proteínas, lípidos y DNA, causando daños y hasta muerte celular (Aro et al., 1993; Inzé \& Van Montagu, 1995). Los cloroplastos son la fuente más importante de EAO's y por ende, las organelas más susceptibles a ellas frente a situaciones de estrés (Casano \& Trippi, 1992; Palatnik et al., 2002). Uno de los indicadores de la presencia de daño oxidativo en los tejidos es el aumento de MDA, intermediario de la peroxidación de lípidos de las membranas celulares (Wang et al., 2009).

Por último, podría afirmarse que los cambios metabólicos sufridos por las plantas sometidas a estrés biótico (PS o enfermas con virus), tales como la desorganización de cloroplastos, reducción de clorofilas, incremento del contenido de MDA, son semejantes a los que acontecen durante un proceso de envejecimiento acelerado, notable sobre todo, en plantas infectadas con MRCV que mueren prematuramente sin llegar a florecer en casi su totalidad. Los resultados del análisis complementario del incremento de azúcares solubles totales, almidón, proteínas solubles y MDA y de la disminución del contenido de clorofilas, ambos relativos a plantas sanas, indicaron ausencia de interacción estadísticamente significativa $(p>0,05)$ entre condición sanitaria y estadio fenológico en que la planta fue tratada. Es decir que no hubo respuesta diferencial de estas variables para las diferentes condiciones sanitarias frente a ninguno de los tres estadios fenológicos considerados.

Tampoco se detectaron diferencias significativas $(p>0,05)$ entre estadios fenológicos y contenido de azúcares solubles totales y de proteínas solubles en plantas infectadas. Del mismo modo, el incremento relativo en el contenido de malondialdehído y la disminución en el de clorofilas en plantas picadas por insectos no virulíferos e infectadas con los aislamientos $\mathrm{ZE}$ o NOA del MRCV, fueron similares en los tres momentos en que la planta fue tratada. En contraposición, el incremento del contenido de almidón $(p=0,0225)$, resultó notablemente superior en plantas infectadas en el estadio de primera hoja emergiendo del coleóptilo (117,40\%), que en las inoculadas en los estadios de cuarta o quinta hojas desplegadas $(53,58 \%$ y $43,70 \%$, respectivamente) (Figura 2).

En la tabla 3 se resumen los valores de las diferentes variables indicadoras de alteraciones fisiológicas en plantas de trigo sanas y en plantas picadas por insectos no virulíferos (PS) e infectadas con aislamiento ZE y NOA del MRCV, en cada uno de los tres estadios fenológicos considerados.

Se confirma experimentalmente la ocurrencia de alteraciones fisiológicas vinculadas a una severa sintomatología en plantas de trigo cuando, en estadios tempranos, éstas son afectadas por MRCV y/o por fitotoxicidad producida durante el proceso alimentario de su principal vector, D. kuscheli. Por tal motivo, si las condiciones climáticas permiten prever la probable ocurrencia de una severa epifitia del Mal de Río Cuarto virus y teniendo en cuenta que el trigo es uno de los principales reservorios invernales de virus e insecto vector, será necesario tomar las medidas pertinentes para controlar esta enfermedad que constituye una amenaza potencial para el cereal de grano fino de mayor relevancia en Argentina.

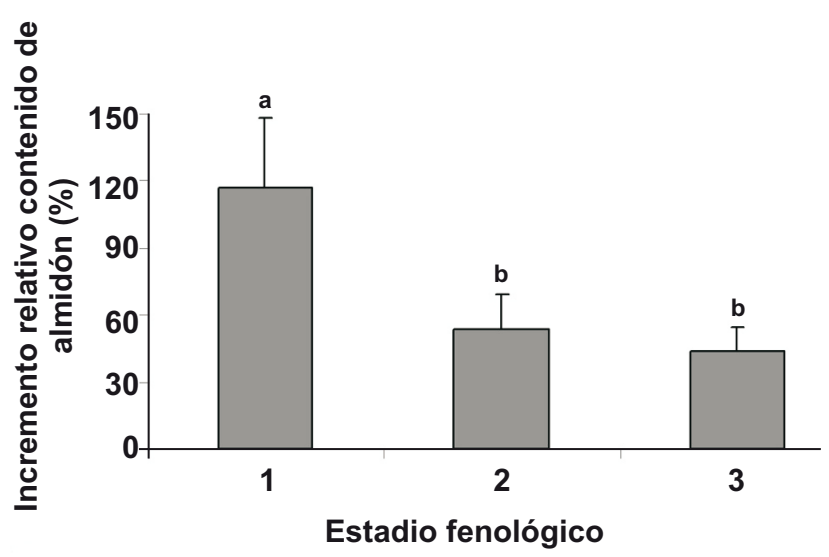

FIGURA 2 - Incremento porcentual de almidón, respecto a plantas de trigo cv ProINTA Federal sanas, para tres estadios fenológicos de picadura por insectos no virulíferos (PS) e infección por aislamiento de Zona Endémica (ZE) y del Noroeste Argentino (NOA) del Mal de Río Cuarto virus (MRCV): 1) primera hoja emergiendo del coleóptilo, 2) cuarta hoja desplegada y 3) quinta hoja desplegada. Letras diferentes indican presencia de diferencias significativas entre los tratamientos $(\mathrm{p}<0,05) . \% \mathrm{IA}=(\mathrm{MCA}-$ MCAS/ MCAS) x 100 (\%IA: incremento porcentual del contenido de almidón relativo a plantas sanas; MCA: media del contenido de almidón en plantas ZE, NOA o PS; MCAS: media del contenido almidón en plantas sanas). 
TABLA 3 - Contenido (promedio + EE) de azúcares solubles totales ( $\mu \mathrm{g} / \mathrm{mg}$ peso fresco), almidón ( $\mu \mathrm{g} / \mathrm{mg}$ peso fresco), proteínas totales ( $\mu \mathrm{g} / \mathrm{mg}$ peso fresco), clorofilas $(\mu \mathrm{g} / \mathrm{mg}$ peso fresco) y MDA $(\mu \mathrm{M} / \mathrm{mg}$ PF) para cuatro condiciones sanitarias: plantas sanas y plantas picadas por insectos no virulíferos (PS) e infectadas con aislamiento de Zona Endémica (ZE) y con aislamiento del Noroeste Argentino (NOA) del Mal de Río Cuarto virus (MRCV) en tres estadios fenológicos (E.F.) diferentes: primera hoja emergiendo del coleóptilo (1), cuarta (2) y quinta hojas desplegadas (3)

\begin{tabular}{|c|c|c|c|c|c|c|c|}
\hline Cond. sanit. & E.F.afe & E.F. & Azúcares solubles & Almidón & Proteínas totales & Clorofilas & MDA \\
\hline Sanas & & & $8,20 \pm 1,93$ & $8,33 \pm 0,90$ & $6,33 \pm 0,20$ & $2,00 \pm 0,13$ & $16,00 \pm 1,9$ \\
\hline \multirow[t]{3}{*}{ PS } & 1 & & $10,5 \pm 1,2$ & $8,75 \pm 0,51$ & $6,73 \pm 0,24$ & $0,93 \pm 0,12$ & $21,5 \pm 2,6$ \\
\hline & 2 & & $11,5 \pm 3,3$ & $9,55 \pm 0,76$ & $6,18 \pm 0,35$ & $1,2 \pm 0,21$ & $30,3 \pm 6,4$ \\
\hline & 3 & & $11,37 \pm 0,98$ & $9,93 \pm 0,83$ & $7,12 \pm 0,35$ & $0,93 \pm 0,10$ & $23,8 \pm 1,6$ \\
\hline \multirow[t]{3}{*}{$\mathrm{ZE}$} & 1 & & $51,3 \pm 14,8$ & $18,33 \pm 2,95$ & $9,83 \pm 1,59$ & $1,2 \pm 0,15$ & $37,73 \pm 3,9$ \\
\hline & 2 & & $13,9 \pm 5,1$ & $13,63 \pm 2,36$ & $8,42 \pm 1,47$ & $1,12 \pm 0,18$ & $34 \pm 9,5$ \\
\hline & 3 & & $13,36 \pm 2,6$ & $11,2 \pm 0,86$ & $8,97 \pm 1,62$ & $0,98 \pm 0,13$ & $23,7 \pm 3,1$ \\
\hline \multirow[t]{3}{*}{$\mathrm{NOA}$} & 1 & & $32,63 \pm 9,3$ & $20,76 \pm 5,48$ & $6,13 \pm 0,78$ & $1,2 \pm 0,10$ & $29,5 \pm 2,1$ \\
\hline & 2 & & $16,9 \pm 8,1$ & $13,83 \pm 4,48$ & $7.62 \pm 0,97$ & $1,52 \pm 0,15$ & $33,9 \pm 3,7$ \\
\hline & 3 & & $42,4 \pm 18$ & $12,67 \pm 1,41$ & $8,87 \pm 1,37$ & $1 \pm 0,18$ & $30,7 \pm 3,6$ \\
\hline
\end{tabular}

\section{REFERENCIAS BIBLIOGRAFICAS}

Aro EM, Virgin I, Andersson B (1993) Photoinhibition of photosystem II. Inactivation, protein damage and turnover. Biochimica et Biophysica Acta 1143:113- 134.

Arias MC, Lenardon SL, Taleisnik E (2003) Carbon metabolism alterations in sunflower plants infected with the Sunflower chlorotic mottle virus. Journal of Phytopathology 151:267- 273.

Arias MC, Luna C, Rodríguez M, Lenardon SL, Taleisnik E (2005) Sunflower chlorotic mottle virus in compatible interactions with sunflower: ROS generation and antioxidant response. European Journal of Plant Pathology 113:223-232.

Arneodo J D, Guzmán FA, Conci LR, Laguna IG, Truol G (2002a) Transmission features of Mal de Rio Cuarto virus in wheat by its planthopper vector Delphacodes kuscheli (Hemiptera: Delphacidae). Annals Applied Biolology 141:195-200.

Arneodo JD, Lorenzo, E, Laguna, IG, Abdala G, Truol, GA(2002b) Cytopathological characterization of Mal de Río Cuarto virus in corn, wheat and barley. Fitopatologia Brasileira 27:298-302.

Backus EA, Serrano MS, Ranger CM (2005) Mechanisms of hopperburn: an overview of insect taxonomy, behavior and physiology. Annual Review of Entomology 50:125-151.

Boccardo G, Milne R (1984) Plant reovirus group. CMI/AAB. Descriptions of Plant Viruses No 294.

Bradford MM (1976) A rapid and sensitive method for the quantification of microgram quantities of proteins utilizing the principle of protein dye binding. Analytical Biochemistry 72:248254.

Bradfute OE, Teyssandier EE, Marino EM, Dodd JL (1981) Reolike virus associated with maize Río Cuarto disease in Argentina. Phytopathology 71:205.

Cafrune EE, Perotto MC, Conci VC (2006) Effect of two Allexivirus isolates on garlic yield. Plant Disease 90:898-904.

Casano LM, Trippi VS (1992) The effect of oxygen radicals on induced proteolysis in isolated chloroplasts. Plant Cell Physiology 33:329- 332 .
Clark MF, Adams AN (1977) Characteristics of the microplate method of enzyme linked immunosorbent assay (ELISA) for the detection of plant viruses. Journal of General Virology 34:475482.

Conti M (1984) Epidemiology and vectors of plant reoviruses. En: K.F.Harris, de., (Ed.) Current Topics in Pathogen-Vector-Host Research, vol. 2 New York NY. Praeger Publishers. pp. 111-139.

Conti M (1988) Recent research on leafhopper vectors of plant virus and mycoplasmas at the Plant Virus Institute Turin. En, Proceedings 6th Auchen Meeting, Torino, Italy. pp. 447-457.

Di Feo L, Biderbost E, Racca R, Nome S, Mollinedo V, López Lambertini P (1995) Incidence of ontogeny and chlorotic dwarf, a viral disease, on the productivity of sweet potato (Ipomoea batatas (L.) Lam) cv Morada INTA. Fitopatología 30:96-99.

Distéfano AJ, Conci LR, Muñoz Hidalgo L, Guzmán FA, Hopp HE, del Vals M (2002) Sequence analysis of genome segments S4 and S8 of Mal de Río Cuarto virus (MRCV): evidence that the virus should be a separate Fijivirus species. Archives of Virology 147:1699- 1709 .

Distéfano AJ, Conci LR, Muñoz Hidalgo L, Guzmán FA, Hopp HE, del Vas M (2003) Sequence and phylogenetic analysis of genome segments S1, S2, S3 and S6 of Mal de Río Cuarto virus, a newly accepted Fijivirus species. Virus Research 92:113-121.

Dujovny G, Usugui T, Shohara K, Lenardon S (1998) Characterization of a potyvirus infecting sunflower in Argentina. Plant Disease 82:470-474.

Gassen DN (2000) Pragas inicias em milho. www.cnpt.embrapa. br/biblio/p_co49.htm Acessado Febrero 16, 2005.

Guan HP, Janes HW (1991) Light regulation of sink metabolism in tomato fruit. II. Carbohydrate metabolizing enzymes. Plant Physiology 96:922-927.

Heath RL, Packer L (1968). Photoperoxidation in isolated chloroplasts. I. Kinetics and stoichiometry of fatty acid peroxidation. Archives of Biochemistry and Biophysics 125:189198.

Hull R (2002) Induction of Disease 1: Virus Movement through the Plant and Effects on Plant Metabolism. En: Matthews Plant 
Virology. San Diego CA. Academic Press. pp. 373-436.

InfoStat (2004). InfoStat, versión 2004. Manual del usuario. Grupo InfoStat/FCA. $2^{\circ}$ edición. Cordoba. Universidad Nacional de Córdoba. Ed. Brujas.

Inzé D, Van Montagu M (1995) Oxidative stress in plants. Current Opinion in Biotechnology 6:153-158.

Iturbe-Ormaetxe I, Escuredo PR, Arrese-Igor C, Becana M (1998) Oxidative Damage in Pea Plants Exposed to Water Deficit or Paraquat. Plant Physiology 116:173-181.

Madhusudhan VV, Miles PW (1998) Mobility of salivary components as a possible reason for differences in the responses of alfalfa to the spotted alfalfa aphid and pea aphid. Entomología Experimentalis et Applicata 86:25-39.

March GJ, Ornaghi JA, Beviacqua JE, Marinelli A (1993) Intensidad del Mal de Río Cuarto y pérdidas causadas a la producción de maíz en las campañas agrícolas 1981/82 a 1991/92. Gaceta Agronómica 13:384-388.

Milne, RG, Lovisolo O (1977) Maize Rough Dwarf and related viruses. Advances in Virus Research 21:267-341.

Milne RG, Boccardo G, Dal Bo E, Nome, SF (1983) Association of Maize Rough Dwarf Virus with Mal de Río Cuarto in Argentina. Phytopathology 73:1290-1292.

Nome SF, Lenardon S L, Raju BC, Laguna IG, Lowe SK, Docampo D (1981) Association of Reovirus-like particles with "Enfermedad de Río Cuarto" of maize in Argentina. Phytopathologische Zeitschrift 101:7-15.

Ornaghi JA, Boito G, Sanchez G, March GJ, Beviacqua J E (1993) Studies on the populations of Delphacodes kuscheli Fennah, in different years and agricultural areas. Journal Genetics Breeding 47:277-282.

Ornaghi JA, March G J, Boito GT, Marinelli A. Beviacqua JE, Giuggia J, Lenardon SL (1999) Infectivity in natural populations of Delphacodes kuscheli, vector of "Mal de Río Cuarto" virus. Maydica 44:219- 223.

Palatnik JF, Valle EM, Carrillo N (2002) Oxidative stress and damage in chloroplasts from dawn to dusk. En: Hemantaranjan A (Eds) Advances in Plant Physiology. Jodhpur. India. Scientific Publishers. Vol. 4, pp. 75-88.
Pastori G, Trippi V (1992) Oxidative stress induces high rate of glutathione reductase synthesis in a drought-resistant maize strain. Plant Cell Physiology 33:957-961.

Remes Lenicov A, Teson A, Dagoberto E, Huguet N (1985) Hallazgo de uno de los vectores del Mal de Río Cuarto del maíz. Gaceta Agronómica 25:251-258.

Rodríguez Pardina PE, Laguna IG, Dagoberto E, Truol GA (1998) Wheat: a new natural host for the Mal de Rio Cuarto Virus in the endemic disease area (Río Cuarto, Cordoba Province, Argentina). Plant Disease 82:149-152.

Sindelárová M, Sindelár L, Burketová L (1999) Changes in glucose, fructose and saccharose metabolism in tobacco plant infected with Potato virus Y. Biologia Plantarum 42:431-439.

Sumner JB, Somers GF (1944) The water soluble polysaccharide of sweet corn. Archives Biochemistry 4:4-7.

Teson A, Remes Lenicov AMM de, Dagoberto EL, Paradell SL (1986) Estudio de poblaciones de delfácidos sobre maíz, avena y maleza circundante (Homoptera-Fulguroidea). GacetaAgronómica 33:507-517.

Tetley RM, Thimann KV (1974) The metabolism of oat leaves during senescence. I. Respiration, carbohydrate metabolism, and the action of cytokinins. Plant Physiology 54:294-303.

Truol GA, Usugi T, Hirao J, Arneodo JD, Giménez Pecci MP, Laguna IG (2001) Transmisión experimental del virus del mal de Río Cuarto por Delphacodes kuscheli. Fitopatología Brasileira 26:39-44.

Uyeda I, Milne R (1995) Introduction: Genomic organization, diversity and evolution of plant reoviruses. Seminars in Virology. Vol. 6. pp. 85-89.

Virla E, Giménez Pecci MP, Herrera S, Conci LR, Laguna IG (1998) Presencia del virus del Mal de Río Cuarto en Tafí del Valle, provincia de Tucumán. Avance Agroindustrial 75:27-30.

Wang JZ, Cui LJ, Wang Y, Li JL (2009) Growth, lipid peroxidation and photosynthesis in two tall fescue cultivars differing in heat tolerance. Biologia Plantarum 53:1192-1198.

Watanabe T, Kitagawa H (2000) Photosyntesis and translocation assimilates in rice plants following phloem feeding by the planthopper Nilaparvata lugens (Homoptera: Delphacidae). Journal Entomology 93:1192-1198. 